\title{
ESTUDO DO MÉTODO DE ULTRASSOM PARA A EXTRAÇÃO DE ÓLEO DE SEMENTES DE UVA PROVENIENTES DE REJEITOS DO PROCESSO VINÍCOLA
}

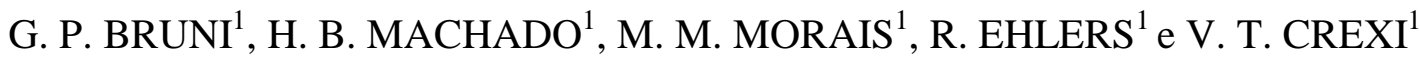 \\ ${ }^{1}$ Universidade Federal do Pampa \\ E-mail para contato: graziellabruni@yahoo.com.br
}

\begin{abstract}
RESUMO - O óleo da semente das uvas Vitis vinifera é conhecido por ter em sua constituição composto benéficos a saúde humana como ácidos graxos insaturados, além de propriedades antioxidantes. Este óleo pode ser extraído a partir de métodos menos usuais como ultrassom, e a eficiência encontrada usando esta técnica tem sido igual ou superior à obtida na extração por solvente a quente. Sendo assim, o objetivo deste trabalho foi estudar o método ultrassom, através da metodologia do planejamento experimental, para extração de óleo de semente de uva da variedade Cabernet Sauvignon e compará-lo ao método de Soxhlet. As variáveis de estudo foram: temperatura e proporção amostra:solvente e a variável de resposta foi a quantidade de óleo extraída. O óleo foi avaliado através do conteúdo de índice de iodo (II), índice de acidez (IA), índice de refração (IR) e perfil de ácidos graxos; avaliou-se também, o rendimento de óleo obtido. A região de trabalho escolhida foi na temperatura de $40^{\circ} \mathrm{C}$ e a relação amostra:solvente ao redor de 1:10. A variedade de semente de uva estudada apresentou em torno de $15 \%$ de óleo e rendimento de extração de $97,74 \%$. Nas análises da qualidade do óleo, encontrou-se para o II de $134,74 \mathrm{~g} \mathrm{I}_{2} / 100 \mathrm{~g}$, IR de $1,4757 \mathrm{e} \mathrm{IA} \mathrm{de} 0,852 \mathrm{~g}$ de ac. oléico/100g. O óleo apresentou cerca de $70 \%$ de ácidos graxos. Constatou-se que método de ultrassom pode ser utilizado como uma alternativa ao método de Soxhlet para se extrair óleo de boa qualidade, utilizando temperaturas inferiores.
\end{abstract}

\section{INTRODUÇÃO}

O processo de fabricação de vinhos gera cerca de 35\% de resíduos (cascas, engaços e sementes), sendo estes geralmente descartados pelas vinícolas, onde o aproveitamento das sementes para a extração de óleo vem se mostrando como uma boa alternativa para a utilização desses resíduos. O óleo de semente de uva pode ser utilizado de diversas formas, seja na indústria alimentícia como na cosmética e farmacêutica (Mendes e Araújo, 2006; LuqueRodríguez et al., 2005).

O óleo da semente das uvas oriundas das variedades Vitis vinifera é conhecido por ter em sua constituição um alto teor de ácidos graxos insaturados, linoléico e oléico, além de apresentar propriedades antioxidantes devido à presença de vitamina $\mathrm{E}$, muito importantes à saúde humana, permitindo o seu uso em dietas que visam diminuir os níveis de colesterol no sangue (Freitas, 2007). 
A extração do óleo da semente de uva pode ser realizada a partir de métodos clássicos, por solvente a quente e prensagem e também por métodos menos usuais, como ultrassom via solvente (Robbers et al., 1997). No método de extração com solvente é utilizado grandes volumes de solvente além de usar um longo tempo para a extração, tornando propícias alterações na composição do óleo devido à decomposição térmica e a reação com solventes (Araújo, 1995; Simões e Spitzer, 1999).

A extração ultrassônica é uma técnica alternativa à extração por solvente a quente e tem sido aplicada para extração de compostos orgânicos de material particulado (Wise et al., 1988). A eficiência de recuperação encontrada usando esta técnica, tem sido igual, ou melhor, do que a obtida na extração por solvente a quente (Eiceman et al., 1980; Blanco et al., 1992). As ondas ultrassonoras causam mudanças físicas e químicas devido à variação de pressão no líquido gerando a cavitação e microfluxos nos líquidos, aquecimento e ruptura nos sólidos e instabilidade na superfície da interface de sistemas líquido-líquido e líquido-gás (Barboza e Serra, 1992; Adewuyi, 2001). O método de ultrassom tem sido aplicado com resultados promissores, por exemplo, na indústria farmacêutica, apresentando como vantagens a simplicidade do equipamento, economia do custo inicial, bem como diminuição do tempo necessário para realização (Barboza e Serra, 1992).

Apesar do método mais utilizado industrialmente ser o de prensagem, este último apresenta alguns pontos negativos com relação ao rendimento do processo e qualidade, tornando importante o estudo de outro método que seja mais vantajoso. Dentre os três métodos de extração, o de ultrassom vem despertando interesse na sua exploração já que possui pontos positivos (tempo, temperatura, rendimento) em relação aos métodos clássicos de prensagem e com solvente a quente.

Pelo que foi exposto, o objetivo deste trabalho foi estudar o método ultrassom para extração de óleo da semente de uva obtida de resíduo vinícola e comparar ao método de extração por solvente a quente (Soxhlet).

\section{METODOLOGIA}

\subsection{Matéria Prima}

Para a realização do trabalho foram utilizadas amostras de sementes separadas dos bagaços da vinificação de uvas da variedade Cabernet Sauvignon. Os bagaços fermentados resultantes da prensagem das uvas para elaboração de vinhos finos, constituídos por sementes, cascas e engaço, foram fornecidos pela vinícola Peruzzo Vinhas \& Vinhos da região de Bagé/RS (safra 2012). Estes resíduos foram acondicionados em sacos plásticos, transportados para o Laboratório de Engenharia de Alimentos da UNIPAMPA campus Bagé e armazenados sob congelamento.

\subsection{Obtenção e preparo da matéria prima}

No processo de limpeza da matéria-prima os resíduos foram peneirados para a separação da semente do bagaço. As sementes, já separadas, passaram por uma lavagem em água corrente até a remoção das impurezas presentes na amostra e foram submetidas ao processo de secagem 
em estufa com circulação de ar a temperatura de $105^{\circ} \mathrm{C}$ durante 1 hora. As condições de secagem (temperatura e tempo) foram estabelecidas conforme preparo da amostra para extração por Soxhlet, uma vez que, será realizada a comparação deste método com o de ultrassom. As sementes inteiras, limpas e secas foram armazenadas em frascos âmbar a temperatura ambiente. Para realização dos experimentos de extração, as sementes foram moídas em moedor analítico Modelo IKA A11 Basic Mill.

\subsection{Metodologia de extração de óleo de semente de uva}

Extração por ultrassom: $\mathrm{O}$ estudo da extração por ultrassom foi realizado com $10 \mathrm{~g}$ de amostra da variedade Cabernet Sauvignon onde o tempo de extração foi 30 minutos para todos os experimentos.

A extração por ultrassom foi realizada em banho ultrassônico Unique (Modelo USC2800A), frequência $40 \mathrm{kHz}$ e potência US: 154w. As amostras de sementes secas e moídas foram colocadas em erlenmeyer de boca esmerilhada juntamente com o solvente Hexano, o qual foi conectado a um condensador. Este aparato foi colocado dentro do banho de ultrassom para extração do óleo. Após a extração via solvente, fez-se a separação da fração sólida por filtração a vácuo e posteriormente separou-se a fração líquida (solvente e óleo) por evaporação do solvente.

Extração por solvente a quente (Soxhlet): A extração por Soxhlet foi realizada empregando-se Hexano (faixa de ebulição de 68-70 C), segundo método do Instituto Adolfo Lutz (2008).

\subsection{Metodologia de análise do óleo de semente de uva}

As amostras de óleo obtidas através do método de Ultrassom (melhor condição obtida a partir dos resultados do planejamento experimental) foram analisadas segundo o Índice de Acidez, Índice de Iodo e Índice de Refração conforme metodologia descrita pelo Instituto Adolfo Lutz (2008). O preparo das amostras para a realização da análise cromatografia para determinação do perfil de ácidos graxos dos óleos foi realizado segundo metodologia descrita por Zambiazi (1997), este método permite a injeção da amostra no equipamento na forma de ésteres metílicos de ácidos graxos. O perfil de ácidos graxos foi determinado com a utilização de um cromatógrafo gasoso-CG (Shimadzu GC-14B), provido com detector FID, com coluna capilar (J $\&$ W Scientific) de dimensão $30 \mathrm{~m} \times 0,252 \mathrm{~mm}$, revestida por filme $0,25 \mu \mathrm{m}$, com fase líquida DB-225 e os dados adquiridos foram processados com auxílio do software Glass-GC10.

\subsection{Metodologia de cálculo para a quantidade e rendimento de óleo}

A quantidade de óleo obtida através dos métodos de extração por solvente a quente (Soxhlet) e ultrassom foi determinada através da Equação 1.

$$
\text { Quantidade de óleo }=\frac{m_{\text {óleo }}}{m_{\text {amostra }}} * 100
$$


Utilizando a Equação 2, determinou-se o rendimento de óleo extraído por ultrassom onde $m_{\text {óleo soxhlet }}$ é a massa de óleo obtido pela metodologia de Soxhlet.

$$
\text { Rendimento de óleo }=\frac{m_{\text {óleo }}}{m_{\text {óleo,soxhlet }}} * 100
$$

\subsection{Metodologia estatística}

Os ensaios de extração foram ordenados segundo uma Matriz de Planejamento Experimental Fatorial Completo $2^{2}$ com ponto central, totalizando 5 ensaios realizados em duplicata.

Os fatores de estudos utilizados na extração por ultrassom foram temperatura de extração e relação quantidade de solvente por peso de amostra, tendo como resposta a quantidade de óleo extraída. Os valores dos níveis dos fatores de estudo utilizados foram determinados a partir de referências bibliográficas (Adam et al., 2012; Freitas, 2007; Zang et al., 2009). Estes autores estudaram a extração via ultrassom de óleos de diferentes fontes lipidicas: a partir de células de microalgas, de sementes de uva das variedades Isabel e Herbemont (Vitis labrusca) e de amêndoas, respectivamente.

A matriz gerada pelo planejamento experimental está representada na Tabela 1.

Tabela 1 - Matriz de planejamento experimental fatorial $2^{2}$ com ponto central nas formas codificada em real

\begin{tabular}{ccccc}
\hline Ensaio & $\mathbf{X}_{\mathbf{1}}$ & $\mathbf{X}_{\mathbf{2}}$ & $\mathbf{T}\left({ }^{\circ} \mathbf{C}\right)$ & Amostra:Solvente \\
\hline 1 & -1 & -1 & 20 & $1: 2$ \\
2 & 1 & -1 & 60 & $1: 2$ \\
3 & -1 & 1 & 20 & $1: 18$ \\
4 & 1 & 1 & 60 & $1: 18$ \\
5 & 0 & 0 & 40 & $1: 10$ \\
\hline
\end{tabular}

Os resultados da matriz do planejamento experimental empregado nos experimentos de ultrassom foram analisados estatisticamente, utilizando software adequado a fim de se obter as variáveis que influenciaram a resposta considerada, bem como as faixas de operação adequadas.

\section{RESULTADOS E DISCUSSÃO}

\subsection{Planejamento experimental}

A Tabela 2 apresenta as variáveis independentes temperatura e relação amostra:solvente na com seus valores reais, bem como quantidade de óleo extraído através do método por Ultrassom durante 30 minutos. 
Tabela 2 - Resultados do planejamento experimental fatorial $2^{2}$ com ponto central para extração por ultrassom durante 30 minutos

\begin{tabular}{cccc}
\hline Ensaio & $\mathbf{T}\left({ }^{\circ} \mathbf{C}\right)$ & Amostra:Solvente & Quantidade de Óleo (\%)* \\
\hline 1 & 20 & $1: 2$ & $8,38 \pm 0,50$ \\
2 & 60 & $1: 2$ & $9,08 \pm 1,50$ \\
3 & 20 & $1: 18$ & $14,56 \pm 0,45$ \\
4 & 60 & $1: 18$ & $15,15 \pm 0,05$ \\
5 & 40 & $1: 10$ & $14,23 \pm 0,40$
\end{tabular}

* Valor médio \pm erro padrão ( $\mathrm{n}=2$ replica dos experimentos).

Através do Diagrama de Pareto (Figura 2) é possível visualizar graficamente os efeitos das variáveis estudadas sobre a resposta, onde os efeitos que apresentaram valores após a linha divisória $(\mathrm{p}=0,05)$ podem ser considerados significativos (95\% de significância). Todos os efeitos foram positivos, ou seja, a quantidade de óleo extraída foi maior ao passar do nível inferior para o nível superior de cada variável; porém, somente a relação amostra:solvente se mostrou significante estatisticamente $(\mathrm{p} \leq 0,05)$. A variável temperatura e a interação entre as duas variáveis independentes não apresentaram efeitos significativos ( $\mathrm{p} \geq 0,05)$.

Na Figura 3 cada um dos vértices do quadrado representa as médias para a quantidade de óleo extraída em cada ensaio nos níveis especificados $(-1,+1)$. A quantidade de óleo variou de 8 , 38 a $15,15 \%$, sendo que os maiores conteúdos de óleo foram obtidos para as condições de extração com relação amostra:solvente 1:18, e no ponto central.

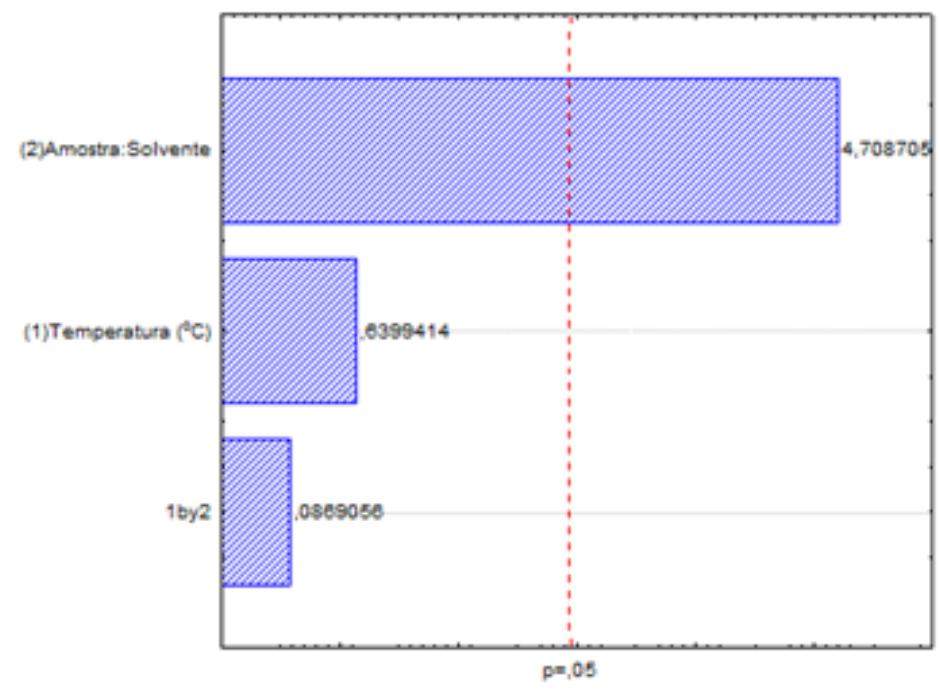

Figura 2 - Diagrama de Pareto

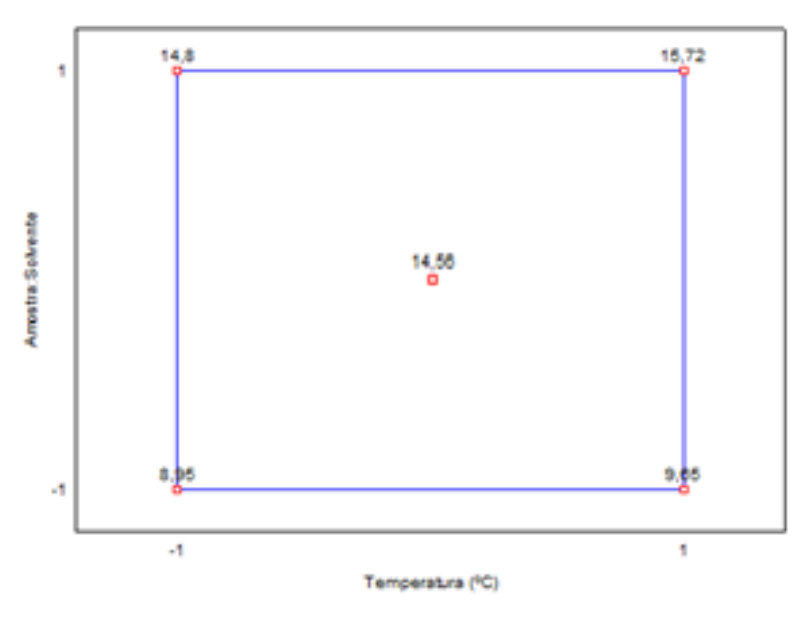

Figura 3 - Quadrado de Resposta

Tendo em vista que os melhores resultados se encontram em torno da maior relação amostra:solvente e que o ponto central demonstrou um comportamento semelhante, seria interessante realizar um novo planejamento experimental em torno das condições de temperatura $40^{\circ} \mathrm{C}$ e relação amostra:solvente $1: 10$, visando-se extrair uma maior quantidade de óleo em uma região de trabalho que utilize menores temperatura e solvente; com isto poderá ser possível reduzir custos com energia e solvente. 


\subsection{Quantidade e rendimento de óleo}

Tanto no método de extração por solvente a quente $(15,50 \%)$ quanto no ultrassom $(15,15 \%)$ a quantidade de óleo obtida foi semelhante. Portto et al. (2013) estudando a comparação do método de extração por Ultrassom com o método convencional Soxhlet para extração do óleo de semente de uva utilizando Hexano como solvente e com parâmetros de extração semelhantes ao deste estudo, encontraram 14,69\% e 14,08\% de óleo para Soxhlet e Ultrassom, respectivamente.

Diante desses resultados e levando em conta que o método de extração por ultrassom utiliza tempo e temperatura menores do que o método de Soxhlet, a escolha pelo método de ultrassom se torna mais interessante e vantajosa. Dessa forma será possível evitar perdas na qualidade do óleo decorrentes da maior temperatura e do maior tempo de extração.

Com relação ao rendimento de óleo esta variedade de semente de uva apresentou rendimento de $97,74 \%$. Estudos utilizando o método do ultrassom têm demonstrado que a eficiência de recuperação utilizando esta técnica tem sido igual, ou melhor, do que a obtida na extração por solvente a quente (Eiceman et al., 1980; Blanco et al., 1992).

\subsection{Características físico-químicas e Perfil de ácidos graxos}

O óleo extraído por ultrassom foi submetido a análises de índice de acidez, iodo e refração, apresentando valores de $0,85 \mathrm{~g}$ de ac. oléico/100g, 134,74 g $\mathrm{I}_{2} / 100 \mathrm{~g}$ e 1,4767 respectivamente.

$\mathrm{O}$ índice de iodo e o índice de refração apresentaram valores dentro dos limites determinados pela ANVISA, os quais encontram-se na faixa de 130 a 138 g I $_{2} / 100 \mathrm{~g}$ e 1,473 a 1,477 respectivamente, porém os valores obtidos para o índice de acidez ficaram acima do máximo permitido pela legislação de $0,3 \mathrm{~g}$ de ac. oléico $/ 100 \mathrm{~g}$. Isso pode ter ocorrido devido à matéria prima ser proveniente da fermentação de processos vinícolas. Outro motivo pode ser relativo às condições desconhecidas em que a mesma se encontrava durante a coleta.

Com base nos limites estabelecidos pela ANVISA para índice de iodo de diferentes óleos, o do óleo de semente de uva é maior do que os dos óleos de arroz $\left(99-108 \mathrm{I}_{2} / 100 \mathrm{~g}\right)$ e de canola $(110$ $\left.126 \mathrm{I}_{2} / 100 \mathrm{~g}\right)$ e apresentou valores que se encontram na faixa dos óleos de soja $\left(120-143 \mathrm{I}_{2} / 100 \mathrm{~g}\right)$ e de girassol (110 - $\left.143 \mathrm{I}_{2} / 100 \mathrm{~g}\right)$ (Brasil, 1999).

Cunha et al. (2009) estudaram a caracterização do óleo de pescado um óleo que também possui propriedades benéficas a saúde devido ao alto teor de ácidos graxos insaturados, e encontrou índice de iodo de $133 \mathrm{~g} \mathrm{I}_{2} / 100 \mathrm{~g}$, bastante semelhante ao encontrado para o óleo de semente de uva.

O Perfil de ácidos graxos do óleo obtido da uva variedade Cabernet Sauvignon está apresentado na Tabela 6.

Tabela 6 - Perfil de Ácidos Graxos do óleo obtido da variedade Cabernet Sauvignon

Ácido Graxo Cabernet Sauvignon* ${ }^{*}$ ANVISA




\begin{tabular}{ccc}
\hline$\Sigma$ AGS & $11,30 \pm 0,02^{\mathrm{a}}$ & - \\
C16:0 (palmítico) & $6,80 \pm 0,01^{\mathrm{a}}$ & $5,5-11,0$ \\
C18:0 (esteárico) & $4,50 \pm 0,01^{\mathrm{a}}$ & $3,0-6,0$ \\
$\Sigma$ AGI & $83,23 \pm 0,02^{\mathrm{a}}$ & - \\
C18:1 (oléico) & $13,10 \pm 0,01^{\mathrm{a}}$ & $12,0-28,0$ \\
C18:2 (linoléico) & $70,13 \pm 0,02^{\mathrm{a}}$ & $58,0-78,0$ \\
$\Sigma A G I / \Sigma A G S$ & 5,35 & - \\
$\Sigma \mathrm{ni}$ & $5,47 \pm 0,01^{\mathrm{a}}$ & - \\
\hline
\end{tabular}

*valor médio \pm erro padrão ( $\mathrm{n}=3$ triplicata), $\Sigma \mathrm{AGS}=$ somatório de ácidos graxos saturados, $\Sigma$ AGI $=$ somatório de ácidos graxos insaturados, $\Sigma$ ni= somatório de não identificados. Letras iguais na mesma linha $(p>0,05)$. Letras diferentes na mesma linha $(p<0,05)$.

Os ácidos graxos que se encontraram em maior quantidade foram linoléico (70,13\%), oléico $(13,10 \%)$, palmítico $(6,80 \%)$ e esteárico $(4,50 \%)$. Os dados obtidos foram similares aos encontrados por GöktürkBaydaret al. (2007), que avaliaram o perfil de ácidos graxos do óleo de bagaço e de semente de uva para outras variedades. Beveridgeet al., (2005), obtiveram resultados similares dos ácidos graxos esteárico $(4,92 \%)$ e oléico $(12,71 \%)$, o conteúdo do ácido graxo linoléico $(72,57 \%)$ ficou acima do encontrado neste estudo.

Os percentuais de ácidos graxos do perfil de ácidos graxos determinados são similares aos citados pela ANVISA (Brasil, 1999). A respeito da relação $\Sigma$ AGI / $\Sigma$ AGS, esta relação foi de 5,35, valor este bem acima do mínimo recomendado pela Health and Social Subjects (1984) que é igual a 0,45 .

\section{CONSIDERAÇÕES FINAIS}

Através do planejamento experimental foi possível determinar a região de trabalho e verificar que a temperatura não influenciou significativamente na quantidade de óleo extraída, dentro da faixa estudada; já a relação amostra: solvente teve influência significativa na resposta, sendo que obteve-se maior quantidade de óleo com uma maior quantidade de solvente. Com base nos resultados encontrados através do planejamento experimental a região de trabalho escolhida foi nas condições de temperatura $40^{\circ} \mathrm{C}$ e relação amostra:solvente ao redor de 1:10 pois foi nesta região que obteve-se maior rendimento no contéudo de óleo extraído. Nos resultados do planejamento experimental os valores encontrados para a quantidade de óleo variaram de 8,38\% a $15,15 \%$.

Os valores encontrados para quantidade de óleo extraída através dos métodos por solvente a quente (Soxhlet) e por ultrassom mostraram-se semelhantes, tornando interessante a escolha pelo uso do método de ultrassom devido à possibilidade de utilizar baixas temperaturas e reduzir o tempo de extração.

A variedade de uva estudada apresentou em torno de 15\% de óleo, rendimento de 97,74\%, alto grau de insaturação podendo assim ser considerado uma rica fonte de ácidos graxos insaturados onde o ácido linoléico, um ácido graxo essencial, apresentou-se em maior quantidade $(\approx 70 \%)$. 
O óleo de semente de uva obtido pelo método de Ultrassom apresentou, os índice de iodo $\left(134,74 \mathrm{I}_{2} / 100 \mathrm{~g}\right)$ e refração $(1,4757)$ dentro dos limites estabelecidos ANVISA, exceto o índice de acidez que apresentou valor maior que o permitido na legislação.

O aproveitamento dos resíduos vinícola para a obtenção do óleo de semente de uva é uma boa alternativa para agregação de valor desses resíduos já que o óleo obtido apresentou valores dentro dos padrões de qualidade estabelecidos pela legislação. Assim, o óleo de semente de uva obtido a partir das melhores condições de extração e conseqüentemente com características aceitáveis para consumo humano pode ser utilizado nas indústrias de fármacos e de alimentos.

\section{REFERERÊNCIAS BIBLIOGRÁFICAS}

ADEWUYI, Y.G. Ind. Eng. Chem. Res. 2001, 40, 4681-4715.

ARAÚJO, J. M. A. Química de Alimentos - Teoria e Prática - Óleos Essenciais. Ed. Impr. Univ. UFV: Viçosa, MG, 1995.

BARBOZA, J. C. S.; SERRA, A.A. O Efeito do ultrassom em reações químicas. Química Nova, SP, 1992.

BLANCO, C.G.; PRADO, J. G.; BORREGO, A.G. Org. Geochem. 1992, 18 (3), 313.

EICEMAN, G.A.; VIAU, A.C.; KARASH, F.W.; Anal. Chem. 1980, 1980, 52, 1492.

FREITAS, L. S.; Desenvolvimento de procedimentos de extração do óleo de semente de uva e caracterização química dos compostos extraídos. Tese de Doutorado, PPGQ, UFRGS, 227p, maio de 2007.

GÖKTÜRK BAYDAR, N.; ÖZKAN, G.; ÇETIN, E. S. Characterization of grape seed and pomace oil extracts. Grasas y aceites, v. 58, n. 1, p. 29-33, 2007.

HMSO. Nutritional aspects of cardiovascular disease. Report on health and social subjects, 46. London: HMSO, 1984.

MENDES, M. A.; ARAÚJO, J. H. B. Transformação de Resíduos da Indústria Vinícola em Produtos de Interesse Comercial. In: Mostra de Iniciação Científica e Tecnologia Interdisciplinar, I. Camboriú, 2006

LUQUE-RODRÍGUEZ J.M., LUQUE DE CASTRO. M.D., PÉREZ-JUAN P. Extraction of fatty acids from grape seed by superheated hexane. Talanta, 2005 - Elsevier.

ROOBERS, J.E.; SPEEDIE, M.K.; TYLER, V.E.; Farmacognosia e Farmacobiotecnologia, Editorial Premier, SP, 1997.

SIMÕES, C.M.O.; SPITZER, V.; In Farmacognosia: da Planta ao Medicamento - Óleos Voláteis; Ed. Universidade/UFRGS/Ed. UFSC, Porto Alegre, RS/Florianópolis, SC, 1999, p 387.

ZAMBIAZI, R. The role of endogenous lipid components on vegetable oil stability. Manitoba/canadá, 1997. 304f. Tese ( Doutorado em Fisiologia), Foodas end Nutritional Sciences Interdepartmental Program, University of Manitoba.

ZHANG, Q-A.; ZHANG, Z-Q.; YUE, X-F.; FAN, X-H.; LI, T.; CHEN, S-F. Response surface optimization of ultrasound-assisted oil extraction from autoclaved almond powder. Food Chemistry 116 (2009) 513-518 